\title{
Perú: Los administradores deben supervisar rutinariamente la calidad de la atención
}

Frontiers in Reproductive Health

Follow this and additional works at: https://knowledgecommons.popcouncil.org/departments_sbsr-rh

Part of the International Public Health Commons, Quality Improvement Commons, and the Women's Health Commons How does access to this work benefit you? Let us know!

\section{Recommended Citation}

"Perú: Los administradores deben supervisar rutinariamente la calidad de la atención," FRONTERAS Resúmenes de Investigación Operativa. Ciudad de México: Population Council, 2000. 


\section{Perú Calidad de la atención}

\section{Resumen de IO 5}

\section{Los administradores deben supervisar rutinariamente la calidad de la atención}

\begin{abstract}
Más del 90 por ciento de los prestadores de servicios de planificación familiar de los centros de salud del gobierno del Perú cumplen con las normas nacionales de atención, dando un trato respetuoso a las clientas y ofreciendo una amplia gama de opciones anticonceptivas. Sin embargo, la mayoría de los proveedores podrían mejorar la calidad de la atención, proporcionando a las clientas mayor información acerca del empleo correcto y de los posibles efectos secundarios del método que hayan elegido, y revisando la presencia de contraindicaciones para su uso. Debe establecerse un estándar de calidad del 100 por ciento para evitar la violación a los derechos reproductivos individuales.
\end{abstract}

\section{Antecedentes}

A finales de la década de los ochenta, el Programa Nacional de Planificación Familiar del Ministerio de Salud (MS) del Perú fijó metas específicas por método a conglomerados de unidades de salud. En 1998, el MS modificó sus políticas para garantizar que los servicios respondieran a las necesidades y los deseos individuales en materia de salud reproductiva. Se eliminaron las cuotas de usuarios por método y las campañas de anticoncepción quirúrgica voluntaria (AQV), y se publicaron normas que garantizaran la calidad de atención y la elección informada.

En 1999, el Population Council colaboró con el MS para determinar si los proveedores estaban acatando las nuevas normas y para desarrollar un sistema de supervisión para evaluar el cumplimiento de dichos lineamientos.

\section{Resultados}

Más del 90 por ciento de los proveedores de planificación familiar del MS trata a sus clientas respetuosamente y les ofrece una variedad de opciones anticonceptivas sin mostrar predisposición a favor o en contra de algún método en particular.
Con todo, los proveedores del MS pueden hacer todavía más para que todas sus clientas reciban información adecuada sobre el método de su elección. Por ejemplo, la mayoría de los prestadores advirtió a clientas simuladas sobre los posibles cambios menstruales asociados con el uso del inyectable DepoProvera (ADMP), pero no mencionaron la posibilidad del retraso en la concepción una vez descontinuado su uso. Las entrevistas realizadas con clientas reales después de sus consultas mostraron conocimientos generales adecuados sobre las pastillas, el condón, los inyectables y la AQV. Sin embargo, los conocimientos específicos sobre el método elegido o utilizado eran incompletos.

En visitas de clientas simuladas, la mayoría de los proveedores de centros de salud urbanos no verificó la presencia de tres de las cuatro condiciones que contraindican el uso del ADMP. Pocos proveedores dieron información sobre los signos de alarma que requieren atención médica.

Más del 90 por ciento de las clientas que habían sido esterilizadas en hospitales, declaró haber decidido por ella misma o junto con el proveedor y 98 
por ciento conocía las consecuencias reproductivas de este procedimiento.

En centros de salud urbanos, la consejería a clientas simuladas duró entre 2 y 45 minutos. Los proveedores transmitieron 43 por ciento más información en sesiones de 9 a 14 minutos que en las de 2 a 8 minutos.

En entrevistas domiciliarias, la mayoría de las clientas de puestos de salud rurales declararon haber decidido por sí mismas usar la anticoncepción, y muchas habían seleccionado ya un método específico antes de acudir al puesto de salud. Sin embargo, sus conocimientos acerca del método elegido eran limitados.

\section{Implicaciones normativas}

- El MS ha emitido y difundido nuevas normas de calidad de atención y ha fortalecido la capacitación y las estrategias de supervisión a sus proveedores.
Se debe evaluar y retroalimentar periódicamente a los centros del MS y a los proveedores individuales respecto a la calidad de su desempeño.

Los proveedores deben invertir todo el tiempo que sea necesario en su interacción con las clientas

Se debe establecer un estándar de calidad del 100 por ciento para evitar violaciones a los derechos reproductivos individuales.

Dos de las cinco modalidades de recopilación de datos (las entrevistas de salida y el uso de clientas simuladas) demostraron ser métodos confiables de monitoreo de la calidad de atención proporcionada en los centros de salud. Las herramientas de monitoreo para hospitales y puestos de salud rurales necesitan mejorarse.

Febrero 2000

\section{Diseño del Estudio}

Para ahorrar tiempo y recursos, el estudio utilizó la técnica de muestreo por lotes para el control de la calidad (LQAS por sus siglas en inglés) con el fin de obtener una muestra de los 6,589 puntos de prestación de servicios en el Perú. La muestra estuvo integrada por 19 hospitales, 19 centros de salud y 19 puestos de salud. En cada punto se realizaron 6 observaciones. La recopilación de datos se llevó a cabo entre junio y agosto de 1999 de la siguiente forma:

(?) La evaluación de los hospitales se realizó utilizando reportes de las clientas simuladas que solicitaban consejería sobre AQV y entrevistas en los hogares de los individuos que optaron por este tipo de anticoncepción.

(- Los centros de salud se evaluaron usando reportes de clientas simuladas que solicitaban DepoProvera y mediante entrevistas de salida a usuarias de planificación familiar.

(ㄴ Los puestos de salud rurales fueron evaluados con los resultados de entrevistas realizadas en los hogares de clientas que habían empezado a usar planificación familiar recientemente.

Para que un elemento cumpla los estándares del LQAS, por lo menos el 95 por ciento de las seis clientas entrevistadas en cada institución debía recibir información específica o un servicio específico del proveedor en por lo menos el 80 por ciento de los establecimientos del muestreo. Se hicieron análisis paralelos con base en intervalos de confianza del 95 por ciento en cada muestra $(\mathrm{N}=114)$.

León, Federico R., 1999. Peru: Providers« Compliance with Quality of Care Norms.

León, Federico R., et al., 1999. Counseling Sessions Length and Amount of Information Exchange in Peruvian Clinics. Para obtener más información escriba o llame a: Population Council-Oficina Regional para América Latina y el Caribe. Escondida 110, Villa Coyoacán, 04000, México. Tel. (52) 55-54-03-88; Fax: (52) 55-54-12-26. Correo electrónico: disemina@ popcouncil.org.mx.

Este proyecto fue posible gracias al apoyo de la Agencia de los Estados Unidos para el Desarrollo Internacional (USAID) bajo el Acuerdo de Cooperación número HRN-A-00-98-00012-00. 